\title{
Validation of the food access survey tool to assess household food insecurity in rural Bangladesh
}

\author{
Muzi $\mathrm{Na}^{1 *}$, Alden L. Gross ${ }^{2}$ and Keith P. West $\mathrm{Jr}^{1}$
}

\begin{abstract}
Background: Perception-based Likert scale are commonly used to assess household food insecurity. The aim of this study was to evaluate the psychometric properties and external construct validity of the 9-item Food Access Survey Tool (FAST) in a population-based randomized controlled trial.

Methods: Participating women $(n=11,992)$ were asked to recall the frequencies of nine food insecurity experiences over the past 6 months on a 5-point Likert scale. The Rasch partial credit model was used to study the item category severity and differential item functioning (DIF) by literacy status, respondents' age, land ownership and household sizes. Principal component analysis (PCA), non-parametric methods, and cumulative ordinal logistic regression models were applied to examine the Rasch model assumptions, namely unidimensionality, monotonicity and measurement invariance (non-DIF).

Results: All items demonstrated good model fit with acceptable values of fit statistics (infit). PCA as well as other indices (Cronbach's alpha $=0.85$, scalability coefficient $=0.48$ ) indicated that all items fit in a single statistical dimension. The ordered responses of nine items displayed monotonic increasing item category severity as expected theoretically. All nine items were flagged with statistically significant DIF between key demographic_-and socioeconomic subgroups $(p<0.001)$; however, none of the detected DIF was considered practically significant given small effect sizes (variance explained by group membership and interaction term $<1 \%$ ). The total summed score over the polytomous FAST was inversely associated with household wealth, dietary diversity score and maternal body mass index, demonstrating external construct validity.

Conclusion: The polytomous FAST is internally and externally valid tool to measure household food insecurity in rural Bangladesh. Validation of this type of studies are recommended for similar Likert food insecurity scales.
\end{abstract}

\section{Background}

Food security is defined by the Food and Agriculture Organization of the United Nations (FAO) as "when all people, at all times, have physical, social and economic access to sufficient, safe and nutritious food that meets their dietary needs and food preferences for an active and healthy life" [1]. Food security can be defined at national, regional, household and individual levels [2]. These scales all rely on three concepts in a hierarchical order: food availability, access, and utilization [3]. In the past two decades, researchers have created and tested many perception-and behavior-

\footnotetext{
* Correspondence: mna1@jhu.edu

'Department of International Health, Johns Hopkins Bloomberg School of Public Health, Center for Human Nutrition, 615 N. Wolfe St., W2041, 21205 Baltimore, MD, USA

Full list of author information is available at the end of the article
}

based Likert scales to capture food access at the household level, which lacks direct measurable indicators [4]. The notion that the coping behaviors reflect severity is rooted from the theory that food insecurity and hunger are "managed processes" [5]. Perceptions and behaviors evolve with progressive difficulty in food access, ranging from psychological concerns to actual compromises in food quality and quantity. The goal of food security scales is to order households along a food insecurity continuum based on how frequently each household displays a range of coping behaviors [2].

The Rasch model, a one-parameter logistic model under item response theory, is recommended [6] and is frequently used in household food insecurity scale development and assessment of the individual items, or questions, that make up the scale [7-12]. The Rasch models estimate food insecurity by allowing different items to have 
different severities which reflect different stages of household food insecurity. The probability of endorsing an item on a logit scale is modeled as a linear function of the overall household food insecurity score and the item's severity. Rasch models assume unidimensionality, monotonicity and local independence of the items within a scale. If those model assumptions hold, there is a desirable property of ordering the latent household food insecurity by a simple summed score of affirmed responses. A continuous food insecurity score from a polytomous scale may allow the use of information from all response category. Previous validation studies employing Rasch modeling have demonstrated the internal validity of using the total number of affirmed items of food insecurity scales with dichotomized indicators. However, research gaps exist in understanding the psychometric properties and model assumption fitness of the polytomous items measuring food insecurity.

Therefore in this study, we examined the internal validity and external construct validity of the total score of a polytomous scale against common indicators of food insecurity. The example we use of a Likert food insecurity scale is the Food Access Survey Tool (FAST) designed by the Food and Nutrition Technical Assistance group for use in Bangladesh [13].

\section{Methods}

\section{Subjects and data collection}

For this validation study, we used data from women who had participated in a cluster-randomized trail comparing efficacy of antenatal multiple micronutrient versus ironfolic acid supplementation on a range of birth and postnatal outcomes in Gaibandha District in rural northwestern Bangladesh. Details of the parent trial are described elsewhere [14]. Briefly, newly pregnant women of reproductive age (13-45 years) consented to participate in the trial and demographic and socio-economic status (SES) were collected at enrollment via a standardized questionnaire. Women were then visited at home at 3 months postpartum, asked about the frequency of dietary intake of 32 foods in the previous 7 days, weighed lightly clothed on SECA digital scales (UNICEF) to the nearest $100 \mathrm{~g}$, measured in terms of height using a portable stadiometer and left mid-upper arm circumference (MUAC) with an insertion tape, both to the nearest $0.1 \mathrm{~cm}$. From the data collected at enrollment, a wealth index using selective SES variables was created according to a previous published methodology [15]. Dietary diversity scores and weight status were determined from data collected at the 3 months postpartum follow-up. Woman's dietary diversity score (WDDS) was calculated following the FAO guidelines [16], ranging from 0 (no food group in the past 7 days) to 10 (maximum diversity). Maternal body mass index (BMI) was calculated as weight/ height ${ }^{2}\left(\mathrm{~kg} / \mathrm{m}^{2}\right)$.
Undernutrition and overweight was defined as a BMI value less than $18.5 \mathrm{~kg} / \mathrm{m}^{2}$ and more than $25.0 \mathrm{~kg} / \mathrm{m}^{2}$, respectively.

At 6 months postpartum, the FAST was used to retrospectively assess household food insecurity in the past 6 months [13]. It consisted of 9 items covering several key domains of household food insecurity experiences [4], including: 1) security and predictability over food acquisition (worrying about food, purchasing rice often, and running out of food); 2) reduction in food quality and/or quantity (eating square meals, eating other grains when rice is preferred, skipping meals, eating less food); 3) socially acceptable behaviors or strategies to augment resources in the context of rural Bangladesh (taking food on credit from shops and borrowing food from relatives or neighbours). Participating women were asked to recall the frequencies of the above 9 situations on a 5-point Likert scale: $0=$ never; $1=$ rarely; $2=$ sometimes; $3=$ often or $4=$ mostly. The question about "square meals" was reversely coded in order to be consistent with higher frequency indicating more severe food insecurity as represented in other items. A total score was created by summing the indexed frequency of all nine items. Households with FAST assessment data entirely missing were excluded, leaving a total sample of 11,992 households included in the analysis.

This study was approved by the national ethical review board, Bangladesh Medical Research Council, Dhaka, and the Institutional Review Board of the Johns Hopkins Bloomberg School of Public Health, Baltimore, Maryland.

\section{Statistical analysis}

We conducted a psychometric validation analysis using the partial credit model, which is an extension of the Rasch model for polytomous responses. The unidimensional partial credit model was chosen because a simple summed score is a sufficient statistic of the latent trait under this model [17]. A simulation study comparing partial credit model with other common polytomous models under the item response theory also suggest small violations of stochastic ordering under various conditions [18]. Therefore, if data upholds model assumptions and fits the partial credit model well, the total summed score should contain sufficient information to order household by the severity of food insecurity. The external construct validity of FAST was examined against common indicators of household food insecurity, such as poverty, maternal food intake and nutritional status.

Specifically, we conducted the following analyses: 1) partial credit model fit assessment; 2) model assumption check; 3) estimation of item category severity; and 4) examination of the FAST external construct validity against proxies of household food insecurity. The R 3.1.1 
(The R Foundation for Statistical Computing) was used to conduct all the analyses. The TAM (Test Analysis Modules) package 1.0-3 was applied to build the partial credit models, calculate model fit statistics, and check model assumptions.

\section{Model fit of the partial credit model}

Under the partial credit model, the probability of a person choosing a response category of an item is modeled as a step logistic model between adjacent categories of both the person's food insecurity latent and item severity parameter. Two Chi-square type statistics, namely Infit and Outfit, are used to evaluate the fit of Rasch models. Both statistics compare the estimated responses by the model with the observed responses. Infit is a weighted statistic giving more weight to the households' food insecurity severity around the estimated item severity, whereas Outfit is unweighted and is more sensitive to outlying responses. In food security scale analyses, Infit is given more priority because it is more informative in population research $[9,12,19]$. The two statistics are commonly expressed as the mean of the summed squared standardized residuals (Mnsq) and standardized t-statistics. Considering stability with sample size for polytomous data, we chose to report squared standardized residuals [20]. A squared standardized residual value of 1.0 is found if the observed data fit the model perfectly. A range of 0.7 to 1.3 is considered acceptable while a narrower range 0.8 to 1.2 is recommended [11]. In this study, we compare Infit Mnsq statistics of all item category parameters with both ranges.

\section{PCM model assumptions}

Belonging to the Rasch model family, there are some key assumptions required: local independence, unidimensionality, monotonicity, and measurement invariance. Local independence states the independent relationship between responses to any two items conditioning on the underlying food insecurity trait. Detecting violations of local independence is challenging [21], therefore this assumption is often assumed or implied from model fit results as did in other validation studies [7, 12, 19]. The examinations of other three assumptions are introduced in more details below.

Unidimensionality refers to a single latent trait being measured by the given scale. In the case of FAST, we expect that only one food insecurity latent trait is necessary to account for the inter-item associations in the data. Various indices have been used to evaluate unidimensionality [22]. Cronbach's alpha, a measure of internal consistency and the Loevinger's scalability coefficient $(H)$, an indicator of homogeneity, were calculated for the entire scale. A cutoff of 0.7 for Cronbach's alpha [23] and 0.4 for $H$ was used as acceptable level [24].
Principal component analysis (PCA) on polychoric correlation matrix was used to detect the number of components among the FAST items [25]. To help determine the significance of unidimensionality, observed eigenvalues from PCA are compared with simulated eigenvalues from parallel analysis, which is based on item correlation matrix that is due to chance alone. Three criteria were set to identify unidimensionality: a) only one component with observed eigenvalue $>1$; b) variance explained by the first component $>2 / 3$ of total variance; and c) the observed eigenvalue $>$ simulated eigenvalue only held true for the first component [22, 26, 27].

Monotonicity indicates that the probability of endorsing a response is a monotonically non-decreasing function of the food insecurity latent trait. It means that households with increasing severity of food insecurity have greater risk of responding to a more severe category than households with less severe food insecurity. The Mokken scale analysis by the R/Mokken package 2.7.5 was used to examine monotonicity. This method compares the probability of endorsing a category or above of the examined item given the sum score of the rest of the items. Detailed methodology and settings are available elsewhere [28]. Briefly, the number of sum score groups is determined by setting the minimum number of subjects per group (denoted as minsize) according to sample size. Smaller values of minsize results in increased number of sum score groups, which increases the sensitivity of the test as well as the probability of violation detection simply due to sampling error. It is recommended to have minsize set at one tenth of the total sample size if sample size is large $(>500)$. In this study where sample size is about 12,000 , we applied the recommended level as well as two stricter minisize levels at one fiftieth and one over five hundred of the sample size.

Measurement invariance indicates that the response behavior to each item on the scale should not differ by the respondent's characteristics that are considered exogenous variables of food insecurity, such as respondents' religion, age, sex, and education level, etc. Measurement invariance of a scale indicates an unbiased scale that is understood similarly across demographic and socio-economic subgroups when they are having similar level of food insecurity. When an item is responded differently by such characteristics, the item is said to have differential item function (DIF). There are two types of DIFs: uniform DIF occurs when an item present consistent degree of DIF across the latent food insecurity trait; however, when non-uniform DIF occurs, the magnitude of DIF varies by food insecurity trait. Because of its ability to simultaneously detect both types of DIFs and its outperformance compared with other 
commonly used the methods [29], the cumulative logits ordinal logistic regression was chosen to examine DIF in the present study. Detailed procedure is described elsewhere [30]. For each item, proportional odds across all 5 response categories is first tested. Because violations occur in all but one item, we loosened the proportional assumption by applying generalized ordered logistic regression methods. The log odds of response in one category or below is modeled as a linear function of total food insecurity score (model 1) and total score, group membership and interaction term between total score and group membership (model 2). Because model 1 is nested within model 2, log likelihood ratio tests were conducted to test the statistical significance of the total DIFs. The effect size of DIF, defined as the difference of R-squared between model 2 and 1 , is used to test the practical significance given large sample size [30]. Significance level is set at p-value of 0.05 and R-squared difference of $13 \%$ for practical significance [30]. DIF was checked across four subgroups, defined by literacy status (literate vs illiterate), age $(<30$ y vs $\geq 30$ y), land ownership (landless vs land owner) and household size $(<4$ vs $\geq 4)$.

\section{Item category severity}

Partial credit model was used to estimate the item category severity along the latent trait. In this model, estimated item step severity parameters are the intersection of adjacent category probability curves, which is not immediately interpretable as item category severity. We instead calculated the Thurstonian thresholds, which is the food insecurity latent score on logit scale at which the probability of choosing a category or higher reaches 0.50 . The Thurstonian thresholds represent item category severity as its definition is similar to the item severity definition of the dichotomous Rasch model [31]. Higher response categories (indicating greater frequencies) with increasing severity along the food insecurity latent is expected.

\section{External validity}

Given the lack of gold standard of household food insecurity, the external validity was tested by comparing the total score of the FAST against the distribution of three proximal indicators: 1) wealth index, a proxy of overall household socio-economic status; 2) WDDS, an predictor of women's dietary quality and nutrient adequacy [32, 33]; and 3) women's BMI, which reflects nutritional status of the women living in the sampled households. Wealth index and WDDS were divided by quartiles, with the Q1 representing lowest $25 \%$ values and Q4 representing highest $25 \%$ values. BMI values was grouped into undernutrition, normal and overweight by conventional cutoffs. A non- parametric rank test was performed to test any linear trend in the association between total score and the continuous proxy indicators.

\section{Results}

\section{Sample characteristics and FAST responses}

The key characteristics of the households and respondents are listed in Table 1. In this rural population, the mean (SD) household size was 4.2 (2.0) individuals. About $65 \%$ of them were literate and about a third (31.9\%) of the women were undernourished. Those data were comparable with the rural statistics from the Bangladesh Demographic and Health Survey 2011 [34]. Table 2 lists the original questions on the scale and the distribution of categorical responses. Item 1 was reversely coded to represent "no square meals" experiences. Cumulatively, $46.7 \%$ of the respondents answered negatively to all nine food insecurity experiences.

\section{PCM model fit assessment}

Infit values after fitting PCM model are plotted in Fig. 1. Among 36 item category parameters, all infit values of those parameters were within the acceptable range of 0.7-1.3, except for two of the infit values of item 8 "take food on credit" (Sometimes $=1.33$ and Often $=1.37$ ). If applying the 0.8-1.2 recommended range, there were four additional infit values that were out of range: item 1 reversed "no square meals" mostly $=1.21$, item 5 "run out of food" rarely $=0.76$, item 7 "purchase rice often" often $=$ 1.29 and item 8 "take food on credit" mostly $=1.28$. In general, infit values indicated acceptable fit of polytomous FAST data to PCM.

Table 1 Characteristics of the study population

\begin{tabular}{|c|c|c|c|}
\hline \multirow{2}{*}{$\frac{\text { Characteristics }}{\text { Household }}$} & \multirow[t]{2}{*}{ N } & \multicolumn{2}{|c|}{ Mean (SD) or \% } \\
\hline & & & \\
\hline Size & 11,980 & 4.2 & $(2.0)$ \\
\hline Dependency ratio ${ }^{a}$ & 11,979 & 0.6 & $(0.4)$ \\
\hline Land ownership & 11,048 & 52.6 & \\
\hline \multicolumn{4}{|l|}{ Women } \\
\hline Age, y & 11,986 & 22.8 & $(5.5)$ \\
\hline Muslim & 11,983 & 91.4 & \\
\hline Literate & 11,981 & 64.7 & \\
\hline WDDS, per week & 11,454 & 5.2 & $(1.7)$ \\
\hline MUAC, cm & 11,552 & 23.4 & $(2.2)$ \\
\hline $\mathrm{BMI}, \mathrm{kg} / \mathrm{m}^{2}$ & 11,532 & 19.6 & $(2.2)$ \\
\hline Undernutrition $(\mathrm{BMI}<18.5)$ & 11,532 & 31.9 & \\
\hline
\end{tabular}

Abbreviations: WDDS women's dietary diversity score; MUAC mid-upper arm circumference; $B M I$ body mass index

aThe dependency ratio was calculated as the number of people aged 0-12 and aged over 50 years living in the family divided by the number of people aged 13-49 years 
Table 2 Item responses to the FAST scale $(N=11,992)$

\begin{tabular}{|c|c|c|c|c|c|c|c|}
\hline \multicolumn{2}{|c|}{ Original question } & \multirow[t]{2}{*}{ Item description } & \multicolumn{5}{|c|}{ Responses (\%) } \\
\hline & & & Never & Rarely & Some-times & Often & Mostly \\
\hline \multicolumn{8}{|c|}{ In the past 6 months, how often did... } \\
\hline Item $1^{\mathrm{a}}$ & $\begin{array}{l}\text { you eat three 'square meals' (full stomach meals) a day } \\
\text { (not a festival day) }\end{array}$ & Square meals & 2.1 & 1.7 & 6.2 & 7.6 & 82.4 \\
\hline Item 2 & $\begin{array}{l}\text { you or any of your family have to eat wheat (or another grain) } \\
\text { although you wanted to eat rice (not including when you were sick)? }\end{array}$ & $\begin{array}{l}\text { Have to eat other } \\
\text { grains }\end{array}$ & 92.7 & 3.2 & 3.2 & 0.7 & 0.2 \\
\hline Item 3 & you yourself skip entire meals due to scarcity of food? & Skip entire meals & 89.0 & 5.8 & 4.0 & 0.9 & 0.3 \\
\hline Item 4 & you personally eat less food in a meal due to scarcity of food? & Eat less & 77.3 & 7.0 & 10.7 & 2.9 & 2.1 \\
\hline Item 5 & $\begin{array}{l}\text { food stored in your home run out and there was no money to buy } \\
\text { more that day? }\end{array}$ & Run out of food & 87.4 & 6.8 & 4.7 & 0.9 & 0.2 \\
\hline Item 6 & you worry about where food would come from? & Worry about food & 85.0 & 5.7 & 6.1 & 1.7 & 1.5 \\
\hline Item 7 & your family purchase rice? & Purchase rice often & 57.9 & 8.5 & 8.2 & 9.5 & 15.9 \\
\hline Item 8 & $\begin{array}{l}\text { your family take food (rice, lentils etc.) on credit (or loan) from } \\
\text { a local shop? }\end{array}$ & Take food on credit & 84.1 & 4.6 & 6.3 & 2.6 & 2.4 \\
\hline Item 9 & $\begin{array}{l}\text { your family have to borrow food from relatives or neighbors to } \\
\text { make a meal? }\end{array}$ & Borrow food & 79.4 & 12.6 & 6.9 & 0.9 & 0.2 \\
\hline
\end{tabular}

atem 1 is reversely coded in analysis and the description for that reversed item 1 is "no square meals"

\section{PCM assumption assessment Unidimensionality}

Cronbach's alpha for the FAST scale was 0.85 and the scalability coefficient $H$ was 0.48 . Both values were above the acceptance cutoff and considered strong. The observed eigenvalues from PCA for components were $5.91,0.85,0.50,0.46,0.40,0.32,0.27,0.15$ and 0.15 . Variance explained by the first component was $65.7 \%$. Only the first component had observed eigenvalue greater than the simulated eigenvalues that ranged from 0.96 to
1.04. Results from PCA showed that all the 9 items fit in a primary statistical dimension, which indicated the assumption of unidimensionality was met.

\section{Monotonicity}

The results from Mokken package are reported in Table 3. The number of active comparison between sum score groups was determined by the number of sum score groups. As the minimum number of subjects per sum score group (minsize) decreased, the number of groups

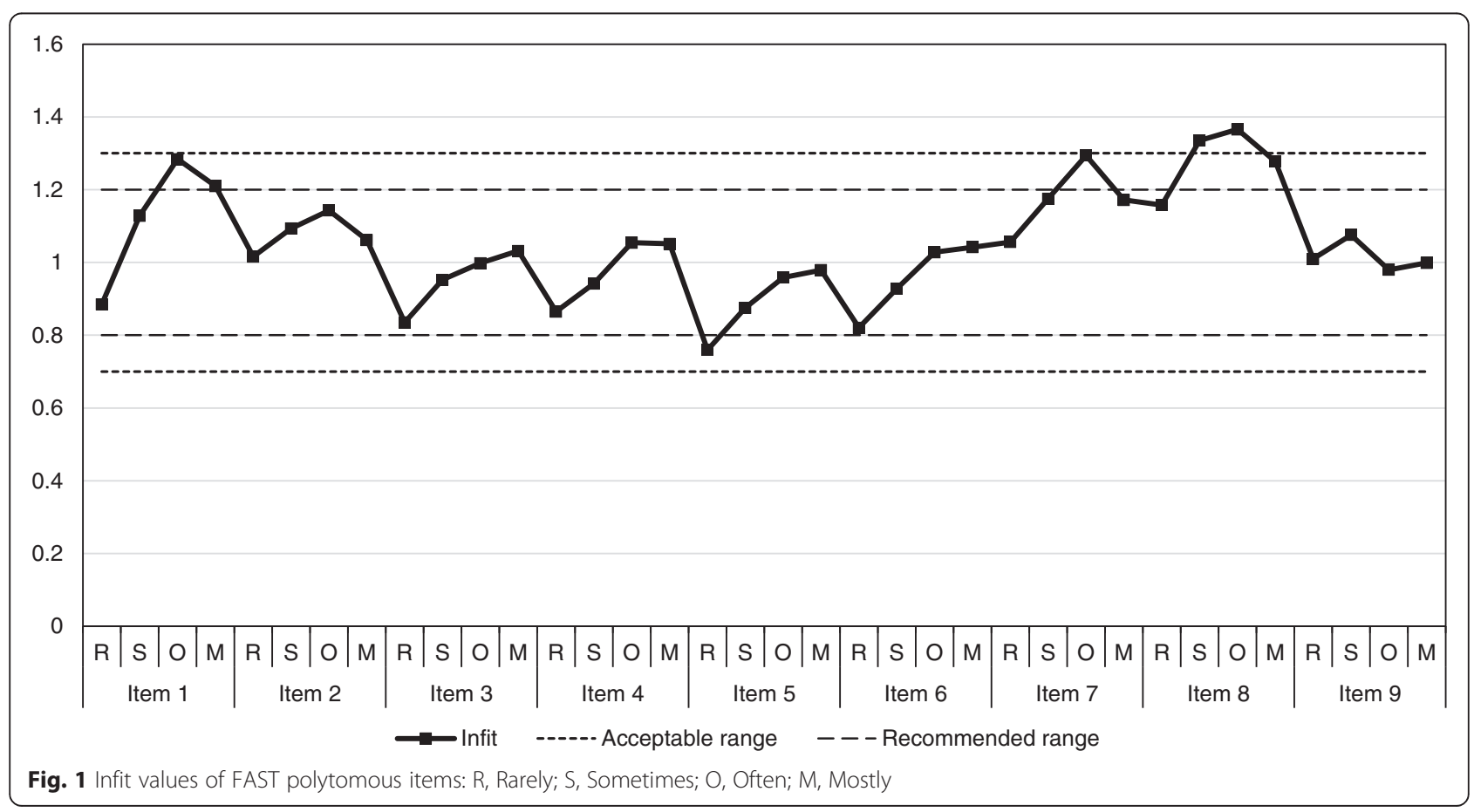


went up so did the number of active comparisons. No significant violation of monotonicity was detected if set the minsize as at the tenth or the one fiftieth level of the total sample size. When setting the minsize at one over five hundred of the sample size, there were 9 to 31 pair comparisons or 1-4\% of total comparisons had local decrease of item response probability as the sum of rest of the items was higher. However, the small proportion of violation was likely due to sampling error because few households have high total score.

\section{Measurement invariance}

The Likelihood ratio tests indicated statistically significant DIF of all items by all four subgroup comparisons, except for item 2 "have to eat other grains" $(p=0.05)$ and item 4 "eat less" ( $p=0.12)$ comparing respondents of younger or older age (Table 4). However, effect sizes of all comparisons were less than $1 \%$, which meant that the additional group membership and the interaction term did significantly improve model fit but did not explain much of the remaining variance. The small effect sizes were all smaller than the cutoff of practical significance.

\section{Item category severity}

In Fig. 2, the histogram on the top represents the distribution of households by their food insecurity latent score on a logit scale. The high bar to the far left represented the $46.7 \%$ households that had reported no food insecurity related experiences to the scale. On the bottom of Fig. 2, item category severity (Thurstonian threshold) of FAST items were reordered by the category severity of the "rarely" response. Item severity estimates for the "rarely", "sometime", "often", and "mostly" category were derived from the step-wise PCM and displayed increasing severity from "rarely" to "mostly" for all items. Estimates of category severity were also dispersed along the logit scale of food insecurity latent trait as expected. Logit is the logodds transformation of the probability of affirming a given category of a scale item. The logit value is expected to be low when the item response category reflects mild food insecurity and high when the category reflects more severe food insecurity. In Fig. 2, the category severity in logit for "rarely" ranged from 0.48 in item 7 "purchase rice often" to 2.49 in item 2 "have to eat other grains". This means households employed different coping strategies at different level of insecurity: when food insecurity was relatively mild, households reallocate resources to purchase rice more often with smaller amount each time; when food insecurity became worse, household members started to sacrifice their amount of food consumed by eating less (item 4), having no square meals (item 1 reversed), skipping the entire meal (item 3 ) and even changing their usual grain preference (item 2). Social acceptable strategies in food acquisition (item 9 "borrow food" and item 8 "take food on credit") were taking place in between the coping strategies of consumption modification. Contrary to the theoretical expectation, however, worrying about food (item 6) did not happen at early stage of food insecurity reflected by a relative higher item severity.

\section{External validity assessment}

The association between the total score of FAST and wealth index, WDDS and maternal BMI is displayed in Fig. 3. Total score was inversely associated with the three proxies, though dose-response pattern was more apparent in the wealth index histogram. The nonparametric rank test resulted $\mathrm{z}$-scores of $-47.9,-19.2$ and -9.9 for significant negative linear trend observed in the continuous wealth index, WDDS and women's BMI, respectively, with increasing total food insecurity scores (all $p<0.001$ ).

Table 3 Monotonicity assessment by Mokken with different minimum number of subjects per score group $(\text { minsize })^{a}$

\begin{tabular}{|c|c|c|c|c|c|c|c|c|c|}
\hline & \multicolumn{9}{|l|}{ Minsize } \\
\hline & \multicolumn{3}{|l|}{$\mathrm{N} / 10$} & \multicolumn{3}{|l|}{$\mathrm{N} / 50$} & \multicolumn{3}{|l|}{$\mathrm{N} / 500$} \\
\hline & $\begin{array}{l}\text { \# active } \\
\text { comparisons }\end{array}$ & \# violations & $\begin{array}{l}\text { \# significant } \\
\text { violations }\end{array}$ & $\begin{array}{l}\text { \# active } \\
\text { comparisons }\end{array}$ & \# violations & $\begin{array}{l}\text { \# significant } \\
\text { violations }\end{array}$ & $\begin{array}{l}\text { \# active } \\
\text { comparisons }\end{array}$ & \# violations & $\begin{array}{l}\text { \# significant } \\
\text { violations }\end{array}$ \\
\hline Item 1 & 40 & 0 & 0 & 312 & 0 & 0 & 1012 & 18 & 1 \\
\hline Item 2 & 40 & 0 & 0 & 344 & 0 & 0 & 938 & 20 & 2 \\
\hline Item 3 & 37 & 0 & 0 & 257 & 0 & 0 & 877 & 10 & 1 \\
\hline Item 4 & 40 & 0 & 0 & 312 & 0 & 0 & 828 & 7 & 0 \\
\hline Item 5 & 21 & 0 & 0 & 228 & 0 & 0 & 730 & 10 & 0 \\
\hline Item 6 & 36 & 0 & 0 & 300 & 0 & 0 & 861 & 9 & 0 \\
\hline Item 7 & 24 & 0 & 0 & 220 & 0 & 0 & 744 & 17 & 1 \\
\hline Item 8 & 40 & 0 & 0 & 312 & 1 & 0 & 1012 & 24 & 0 \\
\hline Item 9 & 36 & 0 & 0 & 268 & 0 & 0 & 865 & 31 & 2 \\
\hline
\end{tabular}


Table 4 Likelihood ratio test between two nested cumulative ordinal logistic regression models for DIF examination

\begin{tabular}{|c|c|c|c|c|c|c|c|c|c|}
\hline & \multirow[b]{2}{*}{ Model $1^{\mathrm{a}}$} & \multicolumn{4}{|c|}{ Literacy (literate vs illiterate) } & \multicolumn{4}{|c|}{ Age ( $\geq 30$ y vs $<30$ y) } \\
\hline & & Model $2^{b}$ & $-2 \mathrm{D}$ & $p$-value & Effect size $^{c}$ & Model $2^{\mathrm{b}}$ & $-2 \mathrm{D}$ & $p$-value & Effect size $^{c}$ \\
\hline Item 1 & -5515.64 & -5496.01 & 39.27 & $<0.001$ & $0.18 \%$ & -5508.65 & 13.98 & $<0.001$ & $0.05 \%$ \\
\hline Item 2 & -3043.47 & -3015.94 & 55.07 & $<0.001$ & $0.60 \%$ & -3040.42 & 6.10 & 0.05 & $0.00 \%$ \\
\hline Item 3 & -3359.23 & -3348.06 & 22.34 & $<0.001$ & $0.16 \%$ & -3348.15 & 22.16 & $<0.001$ & $0.20 \%$ \\
\hline Item 4 & -6012.05 & -5991.26 & 41.56 & $<0.001$ & $0.14 \%$ & -6009.88 & 4.32 & 0.12 & $0.00 \%$ \\
\hline Item 5 & -3244.66 & -3220.84 & 47.64 & $<0.001$ & $0.33 \%$ & -3240.99 & 7.34 & 0.03 & $0.03 \%$ \\
\hline Item 6 & -4281.38 & -4256.09 & 50.59 & $<0.001$ & $0.29 \%$ & -4268.56 & 25.64 & $<0.001$ & $0.14 \%$ \\
\hline Item 7 & -10278.28 & -10184.37 & 187.82 & $<0.001$ & $0.57 \%$ & -10245.95 & 64.66 & $<0.001$ & $0.18 \%$ \\
\hline Item 8 & -6046.82 & -5989.04 & 115.54 & $<0.001$ & $0.68 \%$ & -6035.00 & 23.64 & $<0.001$ & $0.14 \%$ \\
\hline Item 9 & -6296.15 & -6262.50 & 67.29 & $<0.001$ & $0.32 \%$ & -6286.59 & 19.11 & $<0.001$ & $0.10 \%$ \\
\hline \multicolumn{4}{|c|}{ Land ownership (Yes vs No) } & \multicolumn{4}{|c|}{ Household size ( $\geq 4$ vs $<4$ ) } & & \\
\hline & Model $1^{a}$ & Model $2^{\mathrm{b}}$ & $-2 \mathrm{D}$ & $p$-value & Effect size ${ }^{c}$ & Model $2^{\mathrm{b}}$ & $-2 \mathrm{D}$ & $p$-value & Effect size ${ }^{c}$ \\
\hline Item 1 & -5515.64 & -5216.83 & 597.62 & $<0.001$ & $0.23 \%$ & -5502.33 & 26.62 & $<0.001$ & $0.09 \%$ \\
\hline Item 2 & -3043.47 & -2904.33 & 278.28 & $<0.001$ & $0.30 \%$ & -3031.35 & 24.24 & $<0.001$ & $0.22 \%$ \\
\hline Item 3 & -3359.23 & -3218.90 & 280.65 & $<0.001$ & $-0.22 \%$ & -3349.25 & 19.95 & $<0.001$ & $0.14 \%$ \\
\hline Item 4 & -6012.05 & -5714.07 & 595.96 & $<0.001$ & $0.01 \%$ & -5993.87 & 36.35 & $<0.001$ & $0.11 \%$ \\
\hline Item 5 & -3244.66 & -3137.21 & 214.91 & $<0.001$ & $-0.46 \%$ & -3235.91 & 17.50 & $<0.001$ & $0.08 \%$ \\
\hline Item 6 & -4281.38 & -4103.63 & 355.50 & $<0.001$ & $-0.21 \%$ & -4269.68 & 23.41 & $<0.001$ & $0.10 \%$ \\
\hline Item 7 & -10278.28 & -9533.13 & 1490.29 & $<0.001$ & $0.89 \%$ & -10206.68 & 143.19 & $<0.001$ & $0.40 \%$ \\
\hline Item 8 & -6046.82 & -5735.46 & 622.72 & $<0.001$ & $0.09 \%$ & -6033.31 & 27.00 & $<0.001$ & $0.10 \%$ \\
\hline Item 9 & -6296.15 & -5888.44 & 815.41 & $<0.001$ & $0.17 \%$ & -6282.91 & 26.48 & $<0.001$ & $0.04 \%$ \\
\hline
\end{tabular}

${ }^{a}$ Model 1: The log odds of response in one category or below is modeled as a linear function of total food insecurity score only

${ }^{b}$ Model 2: The log odds of response in one category or below is modeled as a linear function of total food insecurity score, group membership and interaction between total score and group membership

'Effect size is defined as the difference of R-squared between model 2 and model 1.c. Effect size is defined as the difference of R-squared between model 2 and model 1

\section{Discussion}

Using data from a large population-based study, we have demonstrated both internal and external validity of using the sum score of polytomous FAST for assessing the level of household food insecurity severity in rural Bangladesh.

The 9-item FAST was developed by comprehensive qualitative and quantitative research [7, 13]. It shares several common features with other existing perceptionbased scales in their short-length nature (9-11 items) and their ability to cover multiple key domains representing progressive stages of food insecurity [4]. One uniqueness of the FAST is its inclusion of a social acceptability domain that has items related to resource augmentation strategies under food insecurity. Consistent with previous validity work for the dichotomous items [7], the additional domain fit well with other domains in one primary statistical dimension. And the ordered responses of all 9 items followed the monotonicity assumption. DIF were flagged on the items on FAST as also found in the previous work [7]. Statistical significance was reached because of large sample size but none has reached practical significance. Model fit results indicated a generally good fit of the data to the partial credit model, which also suggested that the assumptions of the extended Rasch model were likely met.

The item severity were toward the expected theoretical sequence with one exception of the item related to worrying about food. It is believed that psychological concerns happens first when the family senses the threats and constraints to food acquiring [5]. In our sample, "worrying about food" seems to happen after a few coping strategies had already taken place, such as eating less, borrowing food, and eating less square meals. One explanation could be our female only sample. In Bangladesh, women are culturally less in favor of intrahousehold allocation and may sacrifice food quantity when household food insecurity is mild in order to protect her husband and children [35-37]. In addition, due to different social roles by sex in maintaining food security [38], women are more likely than men to borrow food from the kin and neighbors, as demonstrated in the discordance in the item response of female and males under the same households [39]. Because borrowing food is socially acceptable and readily accessible, women may apply such coping strategies at early stage of household food insecurity. On the other hand, if the food 


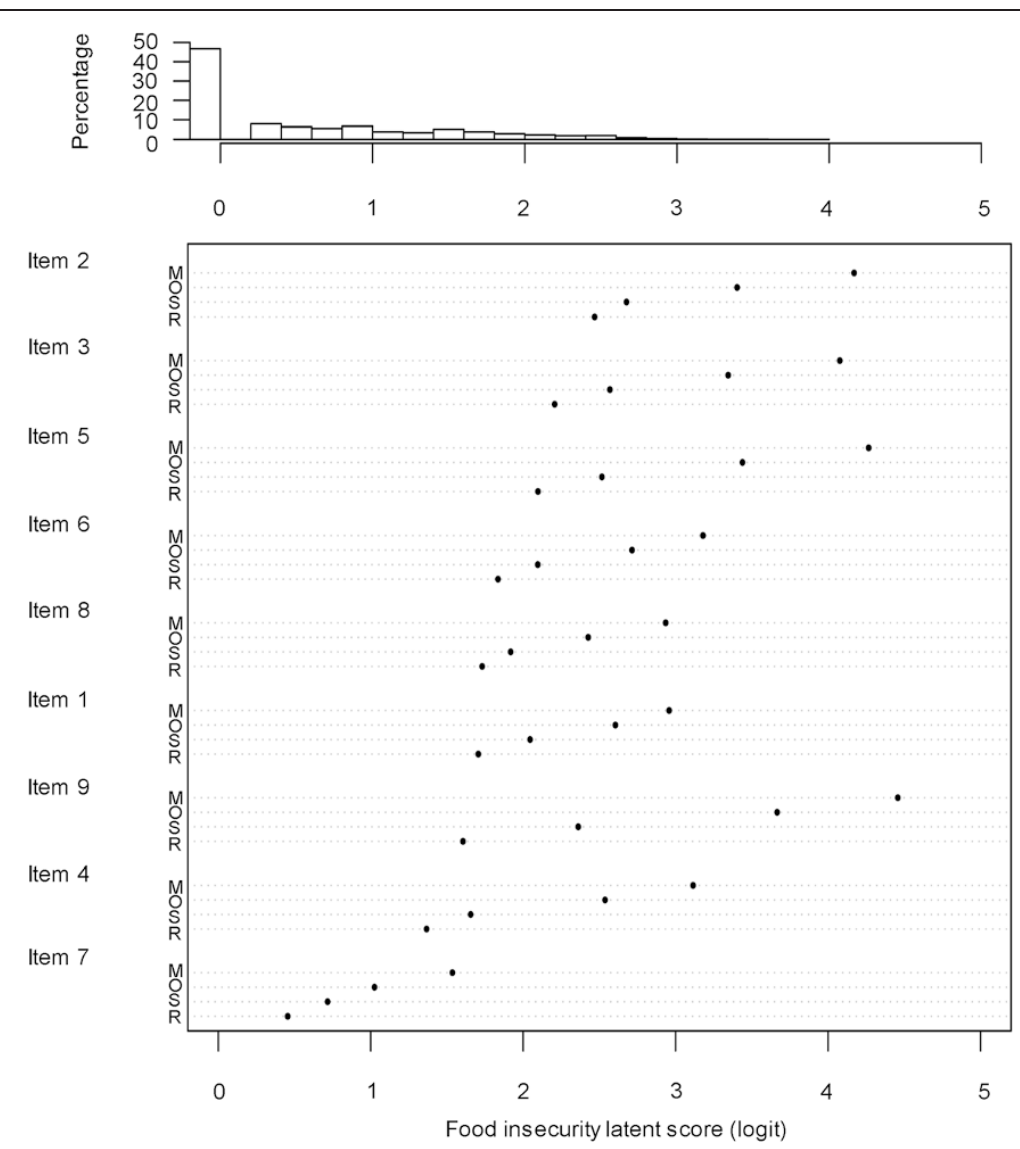

Fig. 2 Distribution of estimated household food insecurity latent score and item category severity (Thurstonian thresholds): R, Rarely; S, Sometimes; O, Often; M, Mostly

insecurity was more chronic than transit in the context, the perception over food acquisition could adapt to high stress situation and remain relatively low in terms of the anxiety level. Given the above reasons, it may be justified that "worrying about food" reflect more severe level of food insecurity in our female sample in rural Bangladesh.
The total summed score of dichotomized items was validated against common food insecurity comparators such as poverty, food consumption, adult BMI and child malnutrition under 12 years old [13]. In our study, we also observed external validity between the total polytomous score and similar food insecurity indicators. The strong association

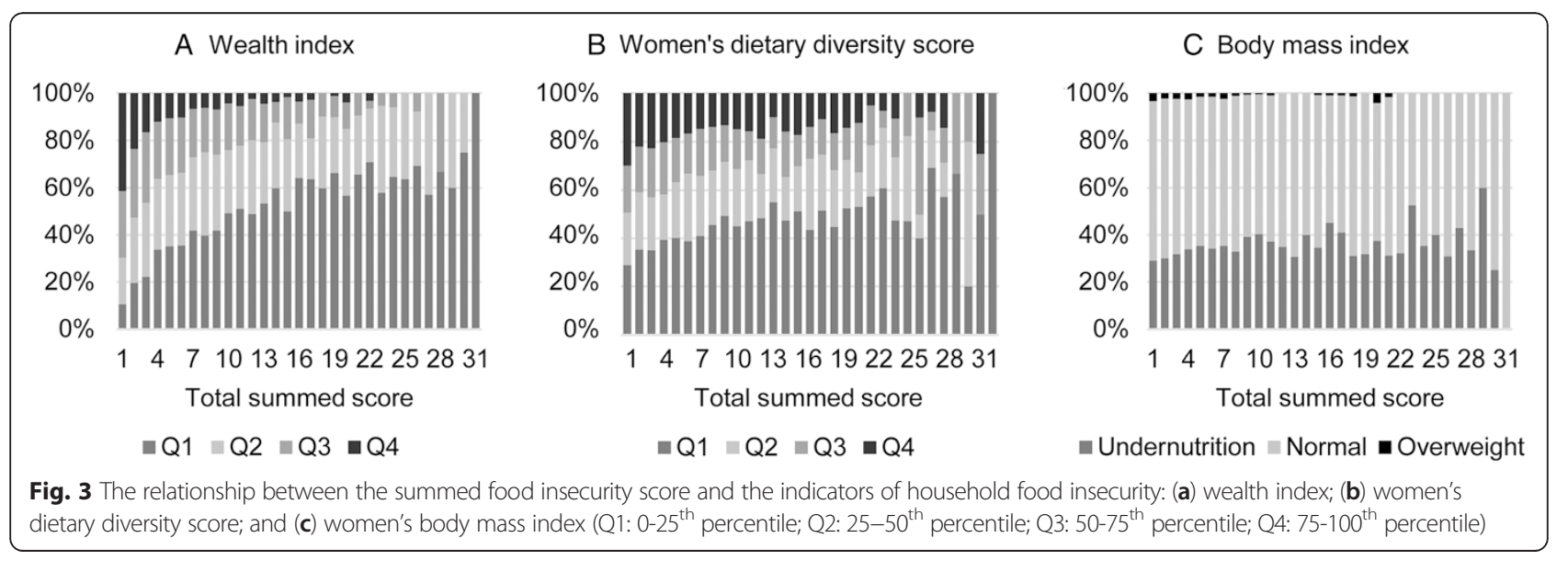


between wealth index and total score was in line with other validation studies comparing a food insecurity index against SES indicators, such as income level [40] and food expenditure [41]. Wealth index was calculated based on a variety of SES indicators capturing a relative static livelihood in this rural setting. The results indicate that food insecurity in rural Bangladesh is a poverty-rooted problem. The weaker association with food quality and maternal nutrition were expected because these are consequences rather than drivers of household food insecurity. More factors play complex roles linking household food access to actual intake (e.g. mechanism of intra-houshold food allocation) and nutritional status (e.g. food and nutrition utilization at individual levels) [42].

Our study has some limitations. First, local independence is assumed rather than tested, although the results from appropriate partial credit model fit implied the assumptions of Rasch model may be met. Second, due to constraints in data collection of the original trial focusing on maternal nutrition and health, external validity was not able to be compared with more proximal drivers or consequences of food insecurity at the household level, such as household income and household food consumption. In this regard, as food manager within the household, but as one whose diet and nutritional status may be particularly sensitive to shifts in home food security, the mother may be viewed as both an optimal and sensitive informant. The three more distal indicators we chose for external validity examination still had expected correlation with the food insecurity index. More investigations are needed to explore the complex mechanism connecting household food insecurity, food intake and nutritional status of household individuals.

\section{Conclusions}

The polytomous FAST is an internally and externally valid tool to measure household food insecurity in rural Bangladesh. The satisfactory model fit and model assumption check of the data to the partial credit model add confidence to use a simple summed score over the polytomous items to order households along their food insecurity latent continuum. Similar procedures examining the internal validity and psychometric property of polytomous items are recommended to other food insecurity scales with different types and number of questions and in other contexts.

\footnotetext{
Abbreviations

FAST: Food Access Survey Tool; DIF: Differential item functioning; PCA: Principal component analysis; FAO: Food and Agriculture Organization of the United Nations; SES: Socio-economic status; MUAC: Mid-upper arm circumference; WDDS: Woman's dietary diversity score; BMI: Maternal body mass index.
}

\section{Competing interests}

The authors declare that they have no competing interests.

\section{Authors' contributions}

MN conceived and designed the validation study, conducted the analysis, managed the review and wrote the first draft of the manuscript. AG contributed to study's technical scope, result interpretation, manuscript writing and revision. KW provided guidance for the design of the study, revised and reviewed drafts of the manuscript. All authors have read and approved the final manuscript.

\section{Acknowledgements}

The study was supported by Bill and Melinda Gates Foundation (Grant OPP 614) and Sight and Life Global Nutrition Research Institute Fellowship. We gratefully acknowledge the analytic guidance of Karen Bandeen-Roche and contributions to the study by Parul Christian, Alain B Labrique, Rolf Klemm, Saijuddin Shaikh, Hasmot Ali, Abu Ahmed Shamim, Rezwanul Haque, Sucheta Mehra, Lee ShuFune Wu and Maithilee Mitra. We thank Amanda Palmer, Sameera Talegawkar and Bess Lewis for their valuable comments on the manuscript.

\section{Author details}

${ }^{1}$ Department of International Health, Johns Hopkins Bloomberg School of Public Health, Center for Human Nutrition, 615 N. Wolfe St., W2041, 21205 Baltimore, MD, USA. ²Department of Epidemiology, Johns Hopkins Bloomberg School of Public Health, Baltimore, Maryland, USA.

Received: 4 December 2014 Accepted: 2 September 2015

Published online: 07 September 2015

\section{References}

1. FAO: Declaration on World Food Security and World Food Summit Plan of Action. World Food Summit 13-17 November 1996. Food and Agriculture Organization: Rome, Italy; 1996. http://www.fao.org/docrep/003/w3613e/ w3613e00.HTM

2. Jones AD, Ngure FM, Pelto G, Young SL. What are we assessing when we measure food security? A compendium and review of current metrics. Adv Nutr. 2013:4(5):481-505.

3. Webb P, Coates J, Frongillo EA, Rogers BL, Swindale A, Bilinsky P. Measuring household food insecurity: why it's so important and yet so difficult to do. J Nutr. 2006;136(5):1404S-8S.

4. Coates J, Frongillo EA, Rogers BL, Webb P, Wilde PE, Houser R. Commonalities in the experience of household food insecurity across cultures: what are measures missing? J Nutr. 2006;136(5):1438S-48S.

5. Radimer KL, Olson CM, Greene JC, Campbell CC, Habicht J. Understanding hunger and developing indicators to assess it in women and children. J Nutr Educ. 1992;24(1):36S-44S.

6. Hamilton WL, Cook JT. Household food security in the United States in 1995: technical report of the food security measurement project. 1997.

7. Coates J, Wilde PE, Webb P, Rogers BL, Houser RF. Comparison of a qualitative and a quantitative approach to developing a household food insecurity scale for Bangladesh. J Nutr. 2006;136(5):1420S-30S.

8. Gulliford MC, Mahabir D, Rocke B. Reliability and validity of a short form household food security scale in a Caribbean community. BMC Public Health. 2004;4:22.

9. Melgar-Quinonez H, Nord M, Perez-Escamilla R, Segall-Correa A. Psychometric properties of a modified US-household food security survey module in Campinas. Brazil Eur J Clin Nutr. 2007:62(5):665-73.

10. Derrickson JP, Fisher AG, Anderson JE. The core food security module scale measure is valid and reliable when used with Asians and Pacific Islanders. J Nutr. 2000;130(11):2666-74.

11. Connell CL, Nord M, Lofton KL, Yadrick K. Food security of older children can be assessed using a standardized survey instrument. J Nutr. 2004;134(10):2566-72.

12. De Toledo V, Rodrigo P, Hromi-Fiedler AJ, Segall-Correa AM, Pérez-Escamilla R. Household food insecurity in small municipalities in Northeastern Brazil: a validation study. Food Security. 2012;4(2):295-303.

13. Coates J, Webb P, Houser R. Measuring Food Insecurity: Going Beyond Indicators of Income and Anthropometry. Washington: Food and Nutrition Technical Assistance Project (FANTA) Academy of Educational Development; 2003.

14. West KP, Shamim AA, Mehra S, Labrique AB, Ali H, Shaikh S, et al. Effect of Maternal Multiple Micronutrient vs Iron-Folic Acid Supplementation on Infant Mortality and Adverse Birth Outcomes in Rural Bangladesh: The JiVitA-3 Randomized Trial. JAMA. 2014;312(24):2649-58. 
15. Gunnsteinsson S, Labrique AB, West Jr KP, Christian P, Mehra S, Shamim AA, et al. Constructing indices of rural living standards in Northwestern Bangladesh. J Health Popul Nutr. 2010;28(5):509-19.

16. Kennedy G, Ballard T, Dop MC. Guidelines for measuring household and individual dietary diversity. Rome: Food and Agriculture Organization; 2010.

17. Masters GN. A Rasch model for partial credit scoring. Psychometrika. 1982;47(2):149-74.

18. der Ark V, Andries L. Stochastic ordering of the latent trait by the sum score under various polytomous IRT models. Psychometrika. 2005;70(2):283-304.

19. Hackett M, Melgar-Quinonez H, Uribe MC. Internal validity of a household food security scale is consistent among diverse populations participating in a food supplement program in Colombia. BMC Public Health. 2008:8:175.

20. Smith AB, Rush R, Fallowfield L, Velikova G, Sharpe M. Rasch fit statistics and sample size considerations for polytomous data. BMC Med Res Methodol. 2008:8:33-2288. 8-33.

21. Deitchler M, Ballard T, Swindale A, Coates J. Validation of a measure of household hunger for cross-cultural use. Washington: Food and Nutrition Technical Assistance II Project (FANTA-2); 2010.

22. Hattie J. Methodology review: assessing unidimensionality of tests and items. Appl Psychol Meas. 1985;9(2):139-64.

23. Bland JM, Altman DG. Cronbach's alpha. BMJ. 1997:314(7080):572.

24. Ligtvoet R, der Ark V, Andries L, te Marvelde JM, Sijtsma K. Investigating an invariant item ordering for polytomously scored items. Educ Psychol Meas. 2010;70(4):578-95.

25. Wold S, Esbensen K, Geladi P. Principal component analysis. Chemometrics Intellig Lab Syst. 1987;2(1):37-52.

26. Kaiser LL, Melgar-Quinonez HR, Lamp CL, Johns MC, Sutherlin JM, Harwood JO. Food security and nutritional outcomes of preschool-age Mexican-American children. J Am Diet Assoc. 2002;102(7):924-9.

27. Timmerman ME, Lorenzo-Seva U. Dimensionality assessment of ordered polytomous items with parallel analysis. Psychol Methods. 2011;16(2):209.

28. Stochl J, Jones PB, Croudace TJ. Mokken scale analysis of mental health and well-being questionnaire item responses: a non-parametric IRT method in empirical research for applied health researchers. BMC Med Res Methodol. 2012;12(1):74.

29. Kristjansson E, Aylesworth R, Mcdowell I, Zumbo BD. A comparison of four methods for detecting differential item functioning in ordered response items. Educ Psychol Meas. 2005;65(6):935-53.

30. Zumbo BD. A handbook on the theory and methods of differential item functioning (DIF). Ottawa: National Defense Headquarters; 1999.

31. Wu M, Adams R: Applying the Rasch model to psycho-social measurement: A practical approach. Educational Measurement Solutions Melbourne 2007. http://hbanaszak.mjr.uw.edu.pl/TempTxt/WuAdams_2006_Applying\%20the\% 20Rasch\%20Model\%20to\%20Psychosocial\%20Measurement\%20A\%20 Practical\%20Approach.pdf

32. Foote JA, Murphy SP, Wilkens LR, Basiotis PP, Carlson A. Dietary variety increases the probability of nutrient adequacy among adults. J Nutr. 2004;134(7):1779-85.

33. Arsenault JE, Yakes EA, Islam MM, Hossain MB, Ahmed T, Hotz C, et al. Very low adequacy of micronutrient intakes by young children and women in rural Bangladesh is primarily explained by low food intake and limited diversity. J Nutr. 2013;143(2):197-203.

34. National Institute of Population Research and Training (NIPORT), Mitra and Associates, and ICF International. Bangladesh Demographic and Health Survey 2011. Dhaka and Calverton: NIPORT, Mitra and Associates, and ICF International; 2013.

35. Shannon K, Mahmud Z, Asfia A, Ali M. The social and environmental factors underlying maternal malnutrition in rural Bangladesh: implications for reproductive health and nutrition programs. Health Care Women Int. 2008;29(8):826-40

36. Abdullah $\mathrm{M}$, Wheeler EF. Seasonal variations, and the intra-household distribution of food in a Bangladeshi village. Am J Clin Nutr. 1985;41(6):1305-13.

37. Kramer EM, Peterson KE, Rogers BL, Hughes MD. Intrahousehold allocation of energy intake among children under five years and their parents in rural Bangladesh. Eur J Clin Nutr. 1997:51(11):750-6.

38. Ali A, Niehof A. Changing gender roles in household food security and rural livelihoods in Bangladesh. In: Ruben R, Pender J, Kuyvenhoven A, editors. Sustainable poverty reduction in less favoured areas. Firstth ed. London: CABl; 2007. p. 228-47.

39. Coates J, Webb P, Houser R, Rogers BL, Wilde P. "He said, she said": who should speak for households about experiences of food insecurity in Bangladesh. Food Sec. 2010;2:81-95.
40. Rose D. Economic determinants and dietary consequences of food insecurity in the United States. J Nutr. 1999;129(2S Suppl):517S-20S.

41. Melgar-Quinonez HR, Zubieta AC, MkNelly B, Nteziyaremye A, Gerardo MF, Dunford C. Household food insecurity and food expenditure in Bolivia, Burkina Faso And the Philippines. J Nutr. 2006;136(5):1431S-7S.

42. Bouis HE, Eozenou P, Rahman A. Food prices, household income, and resource allocation: socioeconomic perspectives on their effects on dietary quality and nutritional status. Food Nutr Bull. 2011;32(1 Suppl):S14-23.

\section{Submit your next manuscript to BioMed Central and take full advantage of:}

- Convenient online submission

- Thorough peer review

- No space constraints or color figure charges

- Immediate publication on acceptance

- Inclusion in PubMed, CAS, Scopus and Google Scholar

- Research which is freely available for redistribution 